\title{
Working in an electronic school iCentre - some practical ideas
}

\author{
Anneli Silvennoinen \\ Teacher Librarian and Head of Department (Library) \\ St Mary's School, Waverley, Johannesburg, South Africa. \\ Correspondence concerning this article should be addressed to \\ St Mary's Senior School, Waverley, \\ Wantage iCentre, PO Box 981, \\ Highlands North, Johannesburg 2037, South Africa. \\ anneli.silvennoinen@stmary.co.za
}

\begin{abstract}
St Mary's Waverley, School for Girls in Johannesburg, South Africa www.stmaryschool.co.za has taken the plunge into the digital and technological world of the $21^{\text {st }}$ century. The Teacher Librarian was consulted on all aspects of updating and modernizing the Library into an iCentre that enhances the learning and teaching experience. The entire school is Wi-Fi connected. The edges of the iCentre, school, home, national and international communities have been blurred. Interactive and collaborative study is the norm. The print collection is enhanced by the Digital Library, website support, Facebook page, online Book Club, digital magazines and newspapers, electronic displays, notices and learning support on mobile devices and a large TV screen. Teaching and learning is online and mobile. Learners are trained in the various ICT skills by means of formal lessons as well as casual Podcamps in the iCentre.

Keywords: St Mary's School Waverley, school library, resource center, iCentre, electronic teaching and learning, collaborative teaching and learning, online teaching and learning, digital library, digital books, digital magazines and newspapers, Apple creativity apps, wikispaces, iTunesU, Facebook, pupil library monitors, staff book club, social media, teenagers, reading promotion, Johannesburg, iCentre staffing, Overdrive digital library, research skills, mobile devices, iPad.
\end{abstract}

\section{Introduction}

\section{The school}

St Mary's School for Girls Waverley in Johannesburg www.stmaryschool.co.za is an independent girls' school established in 1888. Johannesburg was formally established in 1886 with the discovery of gold and the Witwatersrand reef. After the discovery, the population of the city exploded, and Johannesburg became the largest city in South Africa. St Mary's is the oldest school in Johannesburg. Some find it amazing that a girls' school was the first in the city, but in the $19^{\text {th }}$ century, boys were deemed to be more important and they were sent to England to be educated. St Mary's being a member of ISASA (Independent Schools Association of South Africa) is an innovative school achieving amongst the best academic results in the country. The girls range from grade 000 to grade 12 but today we are concerned with the senior school which has about 500 girls from grades 8-12. St Mary's renovated the senior school Resource Centre in 2012 with cutting edge facilities to facilitate teaching and learning in an interactive and interconnected world.

\section{iCentre facilities}


The Resource center renovation was to prepare learners in the skills that keep workers in jobs and business competitive. It was essential to meet the technological requirements of the 21 st century as well as to teach learners critical thinking skills such as evaluating information and the importance of information ethics like acknowledging resources.

Learners are encouraged to consider conflicting points of view and diverse information sources to discover new ideas and form new personal perspectives. Investigation, exploration, search and research challenge learners to go beyond mere answering of questions and finding the correct answer. Collaborative teaching and learning extends beyond the boundaries of the school locally, nationally and internationally. However we recognize that the world is in a transition phase, so are incorporating both the new technology and retaining some print formats as and when required. We also teach both the Apple and the Windows platforms.

Fast speed wireless connectivity throughout the school blurs the boundaries between iCentre, classrooms and home. This enables all teachers and learners to bring their devices to the iCentre and work, whether individually or in classes or small groups. The iCentre consists of mobile iPad laboratories and pods of desktop Windows and Apple computers. These computers are loaded with a wide range of software from Word documents to presentation programs, editing of sound and visuals, creating new information, games and quizzes plus being connected to social media, internet and printers. Electronic booking systems available from any mobile smart device ensure the smooth flowing of facilities.

\section{Staffing}

It is imperative that an iCentre is well staffed with qualified and experienced staff. Our iCentre has staff to cater for the needs of learners and teachers. Anneli Silvennoinen is the Teacher Librarian, Olivia Douglas is her Library Assistant, Linda Bradfield is the ICT Co-coordinator, Candice Macaulay is an ICT teacher and Lilian Southey is the ICT Coordinator's assistant. They all have offices in the Wantage Resource Centre. They are extremely well supported by the team of ICT Helpdesk technical experts, John Berning, Ryan Kuys and Edward Monnakgotla.

The Teacher Librarian accesses resources, teaches and incorporates information and research skills into assignments. The Teacher Librarian also helps learners to master these skills on an individual basis. The Teacher Librarian is computer literate in both the Windows and Apple platforms.

The ICT teacher teaches formal ICT lessons to our learners and is assisted by the Teacher Librarian when dealing with library related topics such as the Digital Library, the Resource Centre FaceBook page, research skills using iTunesU, bibliography compilation and searching the online library catalogue. The ICT teacher runs ICT workshops for our Outreach teachers and manages the ICT training for our pupil Resource Monitors. She also teaches the iPad Genius Group which is a group of girls trained to give iPad assistance during lessons.

The ICT Coordinator is responsible for integrating technology and ICT into the curriculum. She has a computer laboratory consisting of 100 iPads which the teachers can book for their lessons enabling each pupil to work with an iPad. This year's grade eights are expected to have their own iPads and this will develop into everyone as time goes on. St Mary's has been nominated as a Microsoft Innovative Pathfinder School forming a part of a global community of school leaders who work closely together to develop a culture of innovation whilst transforming the way the school operates. The school has supplied each teacher with a laptop and an iPad. All classrooms have interactive whiteboards.

The ICT Coordinator's assistant manages the ICT Club which teaches programming enabling the creation of apps and websites.

A competent and helpful ICT Helpdesk is essential to maintain and help with any hardware and software problems.. The ICT Helpdesk maintains the school network and server onto which all work is saved. Each teacher and learner has their own login to the school wide network. All work is automatically backed up to the server. Girls hand in their work digitally and teachers place work onto the network. 
The whole team works collaboratively to achieve project based teaching and learning.

\section{Teaching and learning}

\section{Print and Digital Library collections}

Our print collection of over 12000 items continues to stock both teen and adult fiction to cater for our younger and older pupils plus staff. The non-fiction collection remains fairly static as the internet has taken over most of the fact finding aspects of research. The fiction collection is much larger than the non-fiction which is a reversal of how things used to be. The non-fiction is hardly used but there are such beautiful books on so many subjects that we often find girls engrossed in reading them to pass the time.

The print collection works together with our Digital Library powered by Overdrive. It is possible to compile custom collection lists in the Digital Library. In this way I curate lists for various research assignments. So the pupils are using books for research but now they are digital books. The learners think it is very 'cool' to find digital library titles on their recommended lists for assignments. By using the app Notability the pupils can make notes, highlight text and email portions of text.

The free app OfflineReader makes it possible for pupils to save text off the internet to be read offline. They can create reading lists from the internet onto their iPads and by clicking on the book icon at the top of the reading list, one is able to read items from the list offline. Pdf documents are saved into iBook's. What we find wonderful is that pupils make notes into the Notes app on their iPads after getting answers to questions in the iCentre and do not bother us again like in the past eg; passwords and how to get started with the Digital Library. The Digital Library makes it possible for users to manage their own accounts, choosing their issue times, doing their own renewals, compiling wish lists for future use, recommending items, reserving items, searching by author, title and subject. Each item has a photograph and a short description to help in choosing digital and audiobooks. Overdrive also has the facility to include music and videos but there are a number of free music downloads on the internet so we have not included this aspect in our digital library collection. Educational YouTube video clips are often used for teaching purposes.

Digital Library items are downloadable onto iPads, laptops, desktops and smartphones. The system is controlled by every user having a unique library card number. Access is via the school website. The Digital Library has greatly sparked interest in reading from our learners especially the formerly reluctant ones. They truly are proving to be a technology orientated generation. We have a reading period every week for grades eight and nine learners and teachers are battling with the concept of how to ensure that learners are truly listening to audiobooks on their earphones! The Teacher Librarian is busy educating teachers that audiobooks are as beneficial as print books. The Digital Library is globally available 24/7 and a great advantage when travelling. It's also great for people who do not want others to know what they are reading on their iPads, such as keen readers not looking like nerds with their books but rather looking 'cool' with their mobile devices.

Teachers have been given special permission to view the Digital Library shop called Market Place. You cannot just buy from anywhere and include the titles in your digital library due to copyright issues. Marketplace has hundreds of available titles and all copyright issues have been cleared by Overdrive. In this way teachers are able to find items they would like to use, and email the information to the Teacher Librarian for purchase. There is also a facility to buy multiple copies for yearlong use, making set books and other items available for a whole class for an extended period. Teachers can also teach a book by downloading copies for themselves and each learner downloads a copy to their device. These copies or extracts are also easy to place onto the interactive whiteboards. All teachers and pupils are encouraged to recommend items for the print and digital collections making the collections user friendly.

\section{Magazines and newspapers}

We currently have ten iPads in the Resource Centre dedicated to magazines and newspapers. We have about 40 magazines and numerous newspapers available from 
educational magazines such as National Geographic to leisure reading such as Teen Vogue. The learners read far more in the digital mode. Interested readers may request the relevant iPads from the Issue Counter, where they are issued to the user on the computerized library administrative system for reading in the iCentre. Formerly patrons came into the Centre to read print magazines and newspapers, now they come into the iCentre to read digital newspapers and magazines. Teachers and pupils are encouraged to recommend magazines and newspapers for the iPads. This system has many advantages over the print system as items are easier to renew, do not get lost and contain numerous features that were impossible in the days of print such as the inclusion of video and auditory files. Older copies are archived for future reference. Magazines and newspapers are bought from the iTunes store, Zinio and Magzter. All iPad covers are color coded according to the department for example resource center iPad covers are red, ICT coordinator's iPad laboratory has black covers and the music department has blue covers.

Overdrive has a facility whereby magazines and newspapers can be added to the Digital Library via the Nook app. Regrettably this facility is only available in the USA.

All subject related magazines are digitally ordered by Heads of Departments and the magazines arrive onto their iPads or laptops. They then email relevant articles to their departmental staff. This ensures that all departmental members get to read these magazines and in their own time. It also closely involves the departments in the selection of magazines and journals in their field. Articles are available without having to photocopy them.

The Teacher Librarian maintains a print collection of general interest in the staffroom to cater for the technologically challenged. This includes magazines and professional development books. However staff members are generally moving more into digital books.

Currently the Teacher Librarian is trying to make it compulsory for each learner to have a copy of the local daily newspaper on their iPads. It does not matter what you read as long as you read. It is the comprehension of text that is important. Reluctant readers are not going to be encouraged by reading a book. They equate their reading reluctance with a book. So make them read a newspaper or a magazine, preferably digital. Then as soon as a pupil finishes their classroom work early, the teacher allows them to read the newspaper on their iPads. I have personal experience of this working. It not only keeps their interest, but improves their comprehension and general knowledge.

\section{Large screen wall mounted TV}

A large screen wall mounted TV connected to a computer is used to do book displays, announce new books in the collections, promote the Digital Library, give handy hints about social networking like etiquette, display notices about happenings in the iCentre, reminders about overdue books, photos, videos, current affairs and any other relevant ideas. Everyone is encouraged to contribute to these displays. Our learners love seeing their work up on the big screen and trying new ideas. This hones their technology skills. The best pupils' book trailers are displayed on the iCentre TV.

This is a wonderful way to display class projects, school plays, art videos done by the learners and numerous other visual and auditory happenings. It is a silent facility with scrolling headlines across the bottom of the screen. Current affairs are also screened with Sky News, CNN and a number of South African channels such as eNCA which also cover African and other international happenings. 


\section{Website and Facebook}

The Resource Centre website at www.stmaryschool.co.za/Senior School/Resource Centre is created and managed by the Teacher Librarian. The website's function has diminished with time as other platforms prove to be more popular and convenient. Today the website includes links to How to compile a Bibliography, the Digital Library and the Resource center Facebook page. The latter is created and managed by the Teacher Librarian. Previously we had a wiki online book club for the pupils. We retained this when we started with Facebook as some pupils' parents forbade them to go onto Facebook. However recently we deleted the wiki as no one was using it and Facebook as a medium of communication has become acceptable.

The Resource Centre Facebook page encourages virtual interaction between pupils about topics such as book recommendations, interesting magazine articles, comments and technical support about social media matters relevant to the iCentre as well as including notices and photographs about iCentre happenings and events. Pupils are encouraged to contribute their ideas. Teachers are not encouraged to join the Facebook page as it might kill interest. However the iCentre staff members are included to monitor the situation. All has gone smoothly and there have been no incidents. However we do not tag our pupils or staff on the site for security reasons. The users themselves can add their photos to their personal sites if they so wish.

\section{Podcamps}

Podcamps are casual groups of learners and staff who join together to learn a new ICT skill in the iCentre. These are voluntary sessions that happen during our lunch breaks. There is no register and no signing up. It is also the only time that food is allowed inside the iCentre as participants may bring their lunch with them. They also bring their mobile devices and the wireless connectivity ensures that we can deal with any topic. These Podcamps are run by Resource Centre staff or our senior Resource Monitors. The skills covered are determined by needs perceived by the teachers and pupils. The advantages of Podcamps are that skills can be reinforced or reintroduced outside of formal lessons and assignments. There is time for individual attention. Podcamps are open to everyone including pupils from grades 8-12, teachers and administrative staff. The participants attend of their own accord and really want to learn. They are very popular and we get about 5-15 attendees at each session. We have run Podcamps on diverse topics and skills such as getting started on the Digital Library, how to use various iPad apps, literary games, book chats, searching the internet, etiquette and use of Facebook, the Dewey system and how the library is organized to learning about various Apple and Windows programs.

\section{Resource Monitors}

The iCentre has a system of Resource Monitors. The pupils are taught various research, computer and library skills. In this way they also are of service to the school community. All our pupils have to do a certain number of hours of community service per school term. The Teacher Librarian has devised booklets with certain skills and criteria that need to be fulfilled to be a Resource Monitor. There are three levels i.e. training, half colors and full colors. These in turn count towards the Service Honours blazer. This system is voluntary but we find that having it count towards something certainly motivates the learners. Skills included in the booklets are computer, research and library skills. The pupils are trained in aspects such as shelving books, downloading magazines and newspapers onto iPads, downloading from and using the Digital Library, searching for items on the online catalogue, doing displays for the TV, managing privacy on the FaceBook page, mentoring their peers, running Podcamps social media etiquette and ethics and various Windows and Apple software programs. The trained Resource Monitors help their peers with queries in the iCentre and train during Podcamps. This is an ideal opportunity for team building and leadership skills to develop. 


\section{Apple Creativity apps}

Apple is on the cutting edge of graphics and technology. The job related design fields are mostly using Apple Macs and the learners love them for graphics, video, art and

photographic work. The Apple Creativity Apps or iLife Suite is very popular. Our learners and teachers love iMovie which enables them to make movies for assignments or presentations of any kind. iMovie is a digital video editor. The process of film capture by a digital camera is automated, with iMovie allowing users to split up their videos, add titles and special effects, and reorganize them into movies. Learners have made movies to form an integral part of our assemblies and much laughter is generated when staff perform their antics as well. Last year the Drama Department learners produced a full length crime movie and had an Oscar's type opening night for the whole school community with red carpets, photographers and ball gowns.

Many subject departments use iBook Author which is a free download that allows teachers to compile an interactive eBook including text, images, widgets, multi choice questions, videos and galleries of images within their lessons for the learners. One of our Art pupils, Katherine Krone, won second prize in a national competition for her artwork made by using iBook Author. Sue Heydenrych, Head of the Art Department, likewise won second prize in the national competition for teachers with her interactive book on Van Gogh. The Teacher Librarian is in the process of creating iBooks about How to compile a bibliography, various library skill lessons, FAQ about the iCentre and an online reference desk. The Teacher Librarian is also investigating an internet based library administration system that will allow the OPAC to be globally mobile. Physically in the Resource Centre, the OPAC can then be taken to the shelves.

The music pupils use Garageband which helps them to learn to play an instrument, write music or record songs. The school's rock band and jazz band entertain the school at events and breaks. The musicians showcase their talents by performing their original compositions. The Photography Club uses iPhoto on iPads to manage and edit their photographs whilst out scouting for photographs. iPhoto is an application that allows users to store, view, edit, and share their digital photos. So the camera and the editing facilities are both out in the field. I teach photography and found that my pupil numbers doubled when I introduced iPads and smartphones as alternatives to normal cameras. Obviously this is for beginners as mobile device cameras cannot do what SLR's can Thandi Mohasa, our Sesotho teacher finds that there is a shortage of resources in Sesotho. Therefore the lower senior school girls are busy making Sesotho vocabulary iBooks for the junior girls. These include images as well as auditory files that help with pronunciation. The grade nines and tens are creating iBooks of simple stories as well as games to test language skills. The Sesotho pupils also have their own radio station consisting of international, national and local news, the weather report, sport and talk shows. This radio is made public monthly during our lunch break. The radio takes music requests from their audience and suddenly the Sesotho girls are popular as all requests have to be in Sesotho. The audience may interact with the radio via sms as long as the messages are in Sesotho. All of this results in a very lively lunch break. The possibilities are endless.

\section{Wikispaces}

Pupils and teachers get very excited about the easy to use environment of wikispaces https://www.wikispaces.com/content/classroom. Global collaboration is achieved through project based learning and teaching. One of our teachers, Caroline Adelaar, was the MS Innovative Forum winner in South Africa. She then went onto the Middle East Africa Forum. Her project entitled Trees4Africa may be viewed at http://trees4africa.wikispaces.com/ Numerous schools throughout Africa joined in Caroline's research project titled Forests in Africa. A project blog page was included. Each group of four pupils was required to research a specific topic and create a page on the class Wiki called Trees4Africa.

A geography teacher, Megan Devine, is collaborating with a school in Japan www.globalbuddies.wikispaces.com . This is a cultural exchange between the two countries 
that teaches world geography. Videos of various aspects are exchanged. These include videos of their homes, arts, culture, food, school, weather and languages.

\section{iTunesU}

The free app iTunes $U$ allows teachers to create, customize, edit and manage their lessons. Edit changes appear in the course instantaneously. The iTunesU platform is useful because you can create courses on Windows or Mac computers to be viewed on iPads.

The Teacher Librarian has created an iTunesU course in Research Skills that is only available on the St Mary's iTunesU space. The iTunesU app requires a code from the teacher to enroll for the course. Each stage of the research process forms a chapter. Each chapter includes teaching notes with added videos and web links to further clarify facts. Each chapter also includes a variety of supplementary media which enhances the learning experience. These can range from worksheets that can be printed and filled in, online sites that compile mind maps, online collaboration tools for group work, online locate and research tool, videos with note taking tips, note taking apps, graphic organizers for pictorial representation of ideas, debate organizers, survey creation apps and the online recording and editing of sound to mention a few.

The Teacher Librarian selects the relevant supplementary tasks for handing in at certain times as proof that the various stages are being accomplished. This also teaches time management.

\section{Reading promotion}

Pupils are encouraged to recommend leisure reading for both the digital and print collections. Recommended reading lists and book recommendations are to be found our Facebook page. This is our online book club. Podcamps on reading are held. The Teacher Librarian is always available to help patrons choose print or digital books according to individual interests A Staff Book Club also meets once a month in the iCentre. It is a casual gathering of interested staff. They may stay for as long as they wish. I normally allocate a one to two hour time slot including our lunch break on a particular day with staff knowing that they have my undivided attention during this time. Some Staff Book Clubs are entirely digital or print and others a combination of the two.

Podcamps and meetings all happen in the iCentre to help draw people to browse and enjoy our book collections. A number of users of all ages including older staff have already downloaded and read eBooks and audiobooks on their devices with no problem. The mini iPad is regarded as welcome as one can hold it in one hand when reading in bed! Technology is usually viewed as a youth thing, but we have noticed that age does not matter. What matters is interest and some elderly users are better than some younger ones. Casual reading nooks are scattered throughout the iCentre where users can settle down and read in peace and quiet.

An idea originally found on Pinterest called Book Tasting https://www.pinterest.com/pin/543387511265582850/ works very well when a class comes in to the iCentre to choose reading books, print or digital. The Teacher Librarian selects appropriate books according to genre and various reading levels. The pupils choose three books with no help from teachers. The pupils have five minutes to read one of the books. Then they make a note into Notes on their iPads listing author, title and genre. Thereafter they have two minutes to write what they thought of the book. This is done for each book. At the end they choose the best of the three books to be issued to them. Their notes can then be emailed to their teacher who gets some idea of the genres and books they like. The advantage is that they select the book and not the teacher. We have had some very reluctant readers actually read their book and even admit that they enjoyed it. This method also teaches book evaluation skills. 


\section{Conclusion}

The iCentre is now able to enhance the teaching and learning experiences of the school by being collaborative in an online world. Technology has changed the world and St Mary's iCentre has embraced this challenge. We are now fully equipped to develop our pupils to meet the 21st century demands of the global community as independent thinkers and creators of new information. This demands life-long learning from all involved. Change is an inevitable part of life and we live in exciting times. School libraries need to embrace the amazing challenges of the technological 21 st century. 